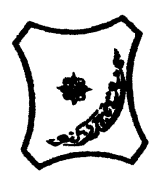

Bayero Journal of Pure and Applied Sciences, 14(1): 1 - 12

Received: December, 2020

Accepted: April, 2021

ISSN $2006-6996$

\title{
HEAVY METALS IN CONTAMINATED SOIL: SOURCE, ACCUMULATION, HEALTH RISK AND REMEDIATION PROCESS
}

\author{
${ }^{{ }^{*}}$ Abdullahi, A., ${ }^{1}$ Lawal, M. A. and ${ }^{2}$ Salisu, A. M. \\ ${ }^{1}$ Department of Chemistry Federal College of Education, Zaria \\ 2Department of Chemistry Federal College of Education, Kano \\ E-mail: aatsaure09@yahoo.com; Phone: +2348036304236, +2348082578499
}

\begin{abstract}
Heavy metals contamination of soil is an issue of global concern that ultimately results in toxicity and diseases in humans and animals through consumption of food crops from contaminated soil. The toxic effects of these metals, even though they do not have any biological role, remain present in some or the other form harmful for the human body and its proper functioning. Heavy metals in the soil refers to some significant heavy metals of biological toxicity, including Cobalt (Co), Cadmium (Cd), Lead (Pb), Chromium (Cr), and Arsenic (As) etc. With the development of the global economy, both type and content of heavy metals in the soil caused by indiscriminate use for human purposes has altered their geochemical cycles and biochemical balance. There are many known sources of harmful metals, including the earth, which releases them into food, air, and water, and anthropogenic activities, such as the application of fertilizer in agriculture, the use of pesticides and herbicides, and irrigation. Other sources are automobile emissions, paints, cigarette smoking, industries, and sewage and waste disposal. This review gives details about some heavy metals their toxicity, bioaccumulation, biodegradation, mobility and solubility in contaminated soil along with their health effects. Remediation of heavy metal in contaminated soils is necessary to reduce the associated risks, make the available soil safe for agricultural production, enhance food security and scale down land tenure problems arising from changes in the land use pattern the review recommends regular monitoring of heavy metals in soil, vegetables and foodstuffs to prevent excessive accrual in food chain.

Keywords: Toxicity, Accumulation, Remediation
\end{abstract}

INTRODUCTION

Metallic elements are intrinsic components of the environment. Their presence is considered unique in the sense that it is difficult to remove them completely from the environment once they enter in it. Metal constitute an important class of toxic substance which are encountered in numerous occupational and environmental circumstances (Grimm et al., 2008). The impact of these toxic agents on human health is currently an area of intense interest due to the ubiquity of exposure. With the increasing use of a wide variety of metals in industry and in our daily life, problems arising from toxic metal pollution of the environment have assumed serious dimensions. Metals are substances with high electrical conductivity, malleability, and luster, which voluntarily lose their electrons to form cations (Khlifi and Hamza-Chaffai, 2010). With a widespread, rapid dissemination of contaminants like heavy metals in agricultural land, the stress on terrestrial ecosystems and societies has substantially increased (Alloway,
2013). Heavy metal pollution in croplands can result in enhanced dietary exposure through soil-plant-food chain transfers (Chaney et al., 2004). The prevention of heavy metals in contaminated soil is not only necessary to control the sources but also to enhance the remediation efficiency of contaminated soils (Zhou et al., 2004).

Concept of Soil

Soil is the valuable resource of a nation whose quality determines its capability to function well for many contended uses (Ideriah et al., 2005). Soil is one of the earth's life sustaining components, it is the most important factor in agricultural production being the main medium for plant growth. The manipulation or management of this resource base has significant influence on the environment or ecosystems because of its effects on water resource, human settlement, atmospheric quality, water and land pollution, vegetation type and distribution, fishery and wildlife (Okonkwo et al., 2005). 
BAJOPAS Volume 14 Number 1, June, 2021

Making plan for having healthy and productive soil is essential to human survival, entrance of materials biological organism or energy into the soil will cause changes in quality. This problem causes soil to remove from its natural state (Agbede and adegoye, 2003).

\section{Definition and Concept of Soil Quality}

Soil is a complex environmental medium with high heterogeneity where solid, liquid and gaseous components interact within a multitude of physical, chemical and biological interrelated processes. Soil provides ecosystem services (benefits people obtain from the soil) such as food, water, timber, and fiber; regulating services that affect climate, floods, disease, waste and water quality; cultural services that provide recreational, aesthetic and spiritual benefits; and supporting services such as nutrient cycling (Ideriah et al., 2005). Soil is one of the important and valuable resources of nature. Life and living on the earth would be impossible without healthy soil. $95 \%$ of human food is derived from the earth. The soil is composed of two parts i.e. soil leaving part and soil dead part. The dead part of the soil includes weathered rocks and minerals which are obtained from the decay of plants and animals, which are called organic matter or humus, water and air, are categorized in this part. Live soil is the soil which includes small animals like insects and worms and plants, fungi, bacteria and other microbes (Coskun et al., 2006). Soil weather in urban or agricultural areas represents a media and sink for release of metals into the environment and also a media in which agricultural crops are produce and the possibility of the crops to take up these metals become obvious (Hong et al., 2014).

\section{Factors and Process of Soil Formation}

Soils form through processes that act on accumulated or deposited geologic (relating to natural crust) material. The characteristics of the soil are determined by the type of material, the organisms (plant and animal life on and in the soil), the climate under which soil forming factors were (and are presently) active, the topography, and the length of time that the forces of soil formation have been active (Van Scholt et al., 2006). The total content of heavy metals in the soil depends primarily on the type of host rock and soil formation factors, the amount of these elements in the soil (in particular level) is changed by the action of anthropogenic and climatic factors (KabataPendias and Pendias, 2001). Soil formation is a constructive as well as destructive process. Destructive process predominates the physical and chemical breaking down of materials, plants and animal structures, which result in the partial loss of more soluble and volatile products. Constructive forces develop new chemical compounds, both mineral and organic and provide new distribution or association characteristics, structural properties as well as chemical compositions (Sarikaya et al., 2003).

\section{Definitions of Heavy Metals}

Different definitions of heavy metals already proposed do exist; some definitions are based on density, atomic number or atomic weight and some on toxicity or chemical properties (Daffus, 2011). The term "heavy metal" refers to as group of toxic metals and metalloids associated with pollution and toxicity having density of more than $6 \mathrm{mg} / \mathrm{cm}^{3}$ and having atomic weight more than that of iron (Ganeshamurthy et al., 2008). Heavy metal are widely recognized and used as a member of loosely defined subset of elements that exhibit metallic character/properties, it mainly includes the transition metals, metalloids, lanthanides and actinides (Ogboru, 2011). Heavy metals can also refer to as any metallic chemical element that have relatively high density and is toxic or poisonous at low concentration. These heavy metals are course of environmental pollution (heavy-metals pollution) from a number of source (Hussein et al., 2012).

\section{Sources of heavy metals in the soil}

Heavy metals are natural constituents of the earth's crust and are persistent environmental contaminants; they are not degradable and entered into the soil in different ways and bioaccumulate over a period of time and the most common heavy metals present in polluted soils are in order of $\mathrm{Pb}, \mathrm{Cr}, \mathrm{As}, \mathrm{Zn}, \mathrm{Cd}, \mathrm{Cu}$ and $\mathrm{Hg}$ (Gray, et al., 1999). Sources of heavy metals pollution in soil include natural processes and anthropogenic activities (Alloway, 2013).

Natural sources: The heavy metals occur naturally in many soils, in different concentrations. The metals in natural, unpolluted soils originate preclusively from the lithosphere, accordingly from the mineral part of the soil that forms the rocks and minerals that make up the Earth's crust (Wang et al., 2016). Naturally present elements reach to the soil from the parent substrate due to pedogenetic processes of weathering of parent materials at levels that are regarded as trace and rarely toxic and volcanic eruptions, sea-salt sprays, forest fires, biogenic sources and wind borne soil particles have also been reported to significantly contribute to heavy metal pollution (Yanagi, 2011).

Anthropogenic sources: Due to different human activities, natural levels of heavy metals in the soil can be exceeded. Soils may become contaminated by the accumulation of heavy 
BAJOPAS Volume 14 Number 1, June, 2021

metals and metalloids through emissions from the rapidly expanding industrial areas, mine tailings, dumping wastes, disposal of high metal wastes, from leaded gasoline and paints, agricultural activities, application of fertilizers and animal manures, sewage sludge, pesticides, wastewater irrigation, coal combustion residues, runoff of terrestrial systems, industrial and domestic effluents, spillage of petrochemicals, accidental leaks, atmospheric deposition (Zhao et al., 2010). The heavy metals are released both in compound (inorganic and organic) and elemental forms. In some cases, metals emitted from these processes continue to build-up in the soil and other environmental compartments even long after these activities have ended. Heavy metals emanating from anthropogenic sources are more dangerous because of their instability and solubility, which leads to a high bioavailability (Armah et al., 2014). Generally, anthropogenic sources of soil contamination can be:

Diffuse (dispersal): which is much more difficult to control (eg agriculture, traffic, surface runoff from urban areas or from agricultural land, atmospheric pollution, wild landfills). (Yanagi, 2011).

Points (concentrated): which are completely locally defined and which can be much easier to control (such as mining, foundries and smelters, and other metal-based industrial operations, wastewaters, industrial effluents). (Wuana and Okieimen, 2011).

\section{Accumulation of Heavy Metals in Soils}

Heavy metals are of considerable concern due to their toxicity, wide source, non biogradable properties and accumulative behaviours (Yu Ruilian et al., 2008). The accumulation of heavy metals in environmental samples represent the potential risk to human health due to the transfer of these elements to aquatic media, their uptake by plants and their subsequent introduction into the food chain, the toxicity, bioavailability and mobility of metals are related to their species (Malandrino et al., 2011). Heavy metals are dangerous because they bioaccumulate. This means that concentration of a chemical in a biological organism becomes higher relative to the environmental concentration (Kampa and Castanas, 2008). Heavy metals pollution of soil enhances plant uptake causing accumulation in plant tissue and eventual phytotoxicity and change of plant community (Gimmler et al., 2002). Accumulation of heavy metals can also cause a considerable detrimental effect on soil ecosystems, environment and human health due to their mobilities and solubilities which determine their specification (Kabata-Pendias, 1992).

\section{Mobility and Solubility of Heavy Metals in Soils}

The amount of heavy metals mobilized in soil environment is a function of $\mathrm{pH}$, properties of heavy metals, redox conditions, soil chemistry, organic matter contents, clay contents, cation exchange capacity and other soil properties (Sauve et al., 2000). Heavy metals solubility and mobility in soils are of environmental significance due to their potential toxicity to both humans and animals (Chirenje et al., 2003). The transfer and chemical stability of metal contaminants in soil and sediments are controlled by a complex series of biogeochemical process depending on variables like $\mathrm{pH}$, clay content and redox potential (Vanbroekhoven et al., 2006). Trace metal mobility is closely related to metal solubility, which is further regulated by adsorption, precipitation and ion exchange reactions in soils (Ma and Dong, 2004).

The transfer of heavy metals from soil to plants is dependent on three factors: the total amount of potentially available elements (quantity factor), the activity as well as the ionic ratios of elements in the soil solution (intensity factor), and the rate of element transfer from solid to liquid phases and to plant roots (reaction kinetics) (Mo et al., 1999). Reduction in redox potential may cause changes in metal oxidation state, formation of new low soluble minerals, and reduction of $\mathrm{Fe}$, resulting in release of associated metals (Baumann et al., 2002). Metal solubility usually increases as the $\mathrm{pH}$ decreases, with the notable exception of metals present in the form of oxyanions or amphoteric species. Since soil solution properties might also be time dependent (Mo et al., 1999).

\section{Bioavialabilty of Heavy Metals in Soils}

Bioavailability refers to the ability of an element to be transferred from the soil to a living organism (Kabata-Pendias and Pendias, 2001). Bioavailability depends on biological parameters and on the physicochemical properties of metals, their ions, and their compounds. These parameters in turn depend upon the atomic structure of the metals, which is symmetrically described by the periodic table (Vanloon and Duffy, 2005). The bioavailability and mobility of metals in soil aqueous phases is controlled by properties such as surface area, surfaces charge (induced by the formation of organic coating on the surface), $\mathrm{pH}$, ionic strength, and concentration of complexing ligand (Petrovic et al., 1999). The $\mathrm{pH}$ and redox potential affects the bioavailabilty of metals in solution: at high $\mathrm{pH}$ elements are present as anions, while at low $\mathrm{pH}$ the bioavailability of metals ions is enhanced (Kabata-Pendias and Pendias, 2001). 
BAJOPAS Volume 14 Number 1, June, 2021

\section{Toxicity of Heavy Metals}

Heavy metals become toxic when they are not metabolized by the body and accumulate in the soft tissues (Sobha et al., 2007) Toxicity of heavy metals refers to the harmful effects that result from exposure or consumption of excessive amounts or more than the daily recommended limits. Although individual metals exhibit specific signs of toxicity, the general signs associated with cadmium, lead, arsenic, cobalt, Nickel, zinc, copper, and aluminium poisoning include gastrointestinal disorders, diarrhoea, stomatitis, tremor, hemoglobinuria, ataxia, paralysis, and vomiting, and convulsion, depression, and pneumonia when vapours and fumes are inhaled (Jaishankar et al., 2014).

\section{Potential Health Risk of Some Selected Heavy Metals}

Arsenic (As): Arsenic is a metalloid in group VA and period 4 of the periodic table that occurs in a wide variety of minerals, mainly as $\mathrm{As}_{2} \mathrm{O}_{3}$, and can be recovered from processing of ores containing mostly $\mathrm{Cu}, \mathrm{Pb}, \mathrm{Zn}, \mathrm{Ag}$ and $\mathrm{Au}$. It is also present in ashes from coal combustion (Singh et al., 2007). Arsenic is one of the most important heavy metals causing disquiet from both ecological and individual health standpoints (Smith et al., 1995). It has a semi metallic property, is prominently toxic and carcinogenic, and is extensively available in the form of oxides or sulfides or as a salt of iron, sodium, calcium and copper. (Singh et al., 2007). Arsenic is the twentieth most abundant element on earth and its inorganic forms such as arsenite and arsenate compounds are lethal to the environment and living creatures. Arsenic is a protoplastic poison since it affects primarily the sulphydryl group of cells causing malfunctioning of cell respiration, cell enzymes and mitosis (Smith et al., 1995).

Cadmium (Cd): Cadmium is an important environmental pollutant present in soil, water, air and food. Anthropogenic sources add 3-10 times more cadmium to the atmosphere than natural sources (Okada, et al., 1997). Major occupational exposure occurs from nonferrous smelters during production and processing of cadmium, its alloys and compounds and the exposure is increasingly common during recycling of electronic waste (Okada, et al., 1997) as well as direct discharges from phosphate fertilizers and sewage sludge, (ATSDR, 2007). Chronic exposure to the metal can lead to kidney disorders, anemia, emphysema, anosmia (loss of sense and smell), cardiovascular diseases, renal problems, and hypertension. Itaiitai disease appears to be a Cd-related disease, which is very painful and causes the wastage and embrittlement of bones (Nishimura et al., 2006). Cadmium is carcinogenic for number of tissue (Waalkes, 2000) and is classified as a human Carcinogen. Cadmium can enter into the brain parenchyma and neutrons causing neurological alterations in humans and animal models leading to lower attention, olfactory dysfunction and memory deficits (Nishimura et al., 2006).

Nickel (Ni): Nickel is silvery white metal that takes on a high polish; it is transition metal, hard and ductile. It occurs most usually in combination with sulphur and iron in pentalandite, with sulphur in millerite, with arsenic in the mineral nickeline and with arsenic and sulphur in nickel glance (Nestle et al., 2002). Nickel combined with other elements is present in all soils; the toxicity of nickel is dependent on the route of exposure (inhalation, oral or dermal) and the solubility of the nickel compounds (Reaves and Baker, 2000). Some of its health risk includes fibrosis, chronic bronchitis, impaired pulmonary function, and emphysema (IARC, 1990). Allergic contact dermatitis is the most prevalent effect of toxicity of nickel in the general population. All nickel compounds, except for metallic nickel have been classified as human carcinogens by the international agency for research on cancer (IARC, 1990) and US department of health and human service.

Lead $(\mathbf{P b})$ : Lead is a metal belonging to group iv and period 6 of the periodic table with atomic number 82 , atomic mass 207.2 , density $11.4 \mathrm{~g}$ $\mathrm{cm}-^{3}$, melting point $327.4{ }^{\circ} \mathrm{C}$, and boiling point $1725^{\circ}$ C. It is a naturally occurring, bluish gray metal usually found as a mineral combined with other elements, such as sulphur (i.e., PbS, $\left.\mathrm{PbSO}_{4}\right)$, or oxygen $\left(\mathrm{PbCO}_{3}\right)$, and ranges from 10 to $30 \mathrm{mg} \mathrm{kg-1}$ in the earth's crust (Stephen, 2000). The main sources of $\mathrm{Pb}$ in the environment include, dust from leaded paints from older houses, leaded and tap water from soldered pipes (Coskun et al., 2006). Indoor chemicals and indoor smoking is also a source (Ganeshamurthy et al., 2008). Lead is probably the least mobile of the heavy metal and has low bioavailability, but due its long residence time in the soil it can be of environmental concern if the levels are high (Duffus, 2002).

Lead has negative influence on both children and adults. For children lead reduces the physical growth and mental growth. The intelligent quotient of children is diminished and symptoms of irritability and fatigue could be observed. Pregnant woman exposed to $\mathrm{Pb}$ can affect physical growth and can cause anemia, kidney damage, headache, hearing problems, speaking problems, fatigue or irritable mood (Coskun et al., 2006). 
BAJOPAS Volume 14 Number 1, June, 2021

Chromium (Cr): Chromium is a first-row $d$ block transition metal of group VIB in the periodic table with the atomic number 24, atomic mass 52 and one of the less common elements and does not occur naturally in elemental form, but only in compounds (Smith et al., 1995). Chromium is present in rocks, soil, animals and plants (Zhao et al., 2012). Chromium occurs in several oxidation states in the environment ranging from $\mathrm{Cr}^{+2}$ to $\mathrm{Cr}^{+6}$ (Rodriguez et al., 2007). The most commonly occurring forms of $\mathrm{Cr}$ are trivalent $\mathrm{Cr}^{+3}$ and hexavalent $\mathrm{Cr}^{+6}$, with both states being toxic to animals, humans and plants (Mohanty and Kumar Patra, 2013). Its occurs naturally by the burning of oil and coal, petroleum from ferro chromate refractory material, pigment oxidants, catalyst, chromium steel, fertilizers, oil well drilling and metal plating tanneries (Ghani, 2011).

The presence of excess chromium beyond the permissible limit is destructive to plants since it severely affects the biological factors of the plant and enters the food chain on consumption of these plant materials (Ghani, 2011). Results obtained from different in vitro and in vivo experiments have shown that chromate compounds can induce DNA damage in many different ways and can lead to the formation of DNA adducts, chromosomal aberrations, sister Chromatid exchanges, alterations in replication and transcription of DNA(Scaragg, 2006). Generally Chromium is associated with allergic dermatitis in humans (Zhang et al., 2010).

\section{Remediation of Heavy Metals in Contaminated Soils}

Heavy metal in soil readily accumulates in plants and is then transported through the food chain, thus becoming a major threat to human health (Mohamed and Ahamadou, 2010). The overall objective of any soil remediation approach is to create a final solution that is protective of human health and the environment (Khan et al., 2008). Remediation is generally subject to an array of regulatory requirements and can also be based on assessments of human health and ecological risks where no legislated standards exist or where standards are advisory (Martin and Ruby, 2004). For heavy metal-contaminated soils, the physical and chemical form of the heavy metal contaminant in soil strongly influences the selection of the appropriate remediation treatment approach. Information about the physical characteristics of the site and the type and level of contamination at the site must be obtained to enable accurate assessment of site contamination and remedial alternatives (Karami et al., 2011).
The contamination in the soil should be characterized to establish the type, amount, and distribution of heavy metals in the soil. Once the site has been characterized, the desired level of each metal in soil must be determined (Chen et al., 1999). These techniques are often used in combination with each other for more economical and efficient remediation of a contaminated site.

(i). Physical Remediation: The physical remediation mainly includes soil replacement method and thermal desorption. The former relies on the use of clean soil to fully or partly replace the contaminated soil with the aim of diluting the pollutant concentration and increasing the soil environmental capacity for the remediation (Qian and Liu, 2000).

- Soil Excavation: the process involves replacing the contaminated soil with new soil. This method is suitable for treatment of small-scale contamination. Excavation and physical removal of the soil is perhaps the oldest remediation method for contaminated soil. It is still in use at many locations, including residential areas contaminated with heavy metals. Advantages of excavation include the complete removal of the contaminants and the relatively rapid cleanup of a contaminated site (Faisal et al., 2004). Disadvantages include the fact that the contaminants are simply moved to a different place, where they must be monitored; the risk of spreading contaminated soil and dust particles during removal and transport of contaminated soil; and the relatively high cost. Excavation can be the most expensive option when large amounts of soil must be removed or disposal as hazardous or toxic waste is required (Baumann et al., 2002).

- Soil spading: The process involve deeply digging the contaminated soil, inducing the pollutant spread into the deep sites to achieve dilution and natural degradation (Zhang et al., 2014).

- New soil importing: Involve adding a large amount of clean soil into the contaminated soil, covering the surface (or mixing) to reduce pollutant levels. Soil replacement can effectively isolate the soil and ecosystem, thus decreasing the effect of pollutants on environment. This technology is costly and suitable just for soil in small area (Zhou et al., 2004).

- Soil isolation: Soil isolation means to separate the heavy metals contaminated soil from the uncontaminated soil, but for complete remediation it still needs other auxiliary engineering measures (Zheng and 
BAJOPAS Volume 14 Number 1, June, 2021

Wang, 2002). Isolation technologies are generally designed to prevent off-site movement of heavy metals and other contaminants by restricting them within a specified area (Zhu et al., 2012). Soil isolation technology is used to avoid further contamination of groundwater by heavy metals when other remediation methods are not economically or physically feasible. In somecases, contaminated sites are isolated temporarily in order to avoid transport during site assessment and remediation.

(ii). Thermal desorption: The process involves heating the contaminated soil using steam, microwaves, and infrared radiation to volatilize the pollutants such as mercury $(\mathrm{Hg})$ and Arsenic (As) (Li et al. 2010).

- Vitrification Remediation: The mobility of heavy metals inside soil can be reduced by applying high temperature treatment at the contaminated site that leads to the formation of vitreous material (Mallampati et al., 2015). During vitrification, some metal species $(\mathrm{Hg})$ may be volatilized under high temperature that must be collected for further disposal or treatment (ESTCP 2000). Vitrification is not considered a classical metal remediation technique but the process is comparatively easy to apply compared to other physical remediation methods. Vitrification can be applied to majority of soils contaminated with inorganic (heavy metals) and organic contaminants. During insitu vitrification, electric current is passed through the soil by vertically inserting an array of electrodes into the contaminated area (ESTCP 2000). However, dry soil may not provide enough conductances for vitrification. The process may not be appropriate for sites where contaminated soil exists directly to buildings, other structures, or the property line (Li et al., 2010).

- Electrokinetic Remediation: Soil electrokinetic remediation is a new and cost effective physical method for the remediation of heavy metals. Soil electrokinetic remediation operates on the principle that the electric field gradient of suitable intensity is established on two sides of the electrolytic tank containing saturated contaminated soil. Heavy metals present in the soil are separated via electrophoresis, electric seepage or electro migration, and thus decrease the contamination (Yao et al., 2012). The method performs well in the soil with low permeability (Luo et al., 2004), while being advantageous to easily install, operate, and undestroyed the original natural environment at low cost (Alshawabkeh and Bricka 2013).

(iii). Chemical Remediation: Chemical remediation involves the use of chemicals to extract or stabilize pollutants in contaminated media. There are several chemical remediation methods including chemical leaching (soil washing), immobilization techniques and stabilization method (Tampouris et al., 2001). These techniques either remove risk by chemically degrading hazardous substances or achieve stabilization of the contaminants within the bulk matrix by breaking pollutant linkages (Ou-Yang et al., 2010).

- Soil washing: The principle of soil leaching is to wash the heavy metal contaminated soil with specific reagents and thus remove the heavy metal complex and soluble irons adsorbed on the solid phase particles. By using this method, heavy metals are separated from the soil and heavy metals are then recycled from extracting solution (Tampouris et al., 2001). Chemical leaching consists of washing the contaminated soil with fresh water, reagents and others fluids (or gas) to leach pollutants from the soil. The process is cost effective because it can reduce the quantity of material that would require further treatment. (Ou-Yang et al., 2010).

- Immobilization Techniques: Chemical fixation is adding reagents or materials into the contaminated soil to form insoluble or hardly movable, low toxic matters; it can thus decrease the migration of heavy metals to water, plant, and other environmental media (Zhou et al. 2004). If the soil immobilization technique is employed, simplicity and rapidity (besides high public acceptability) will be achieved. This method is relatively inexpensive, while covering a broad spectrum of inorganic pollutants. However, immobilization is only a temporary solution (contaminants are still in the environment), the activation of pollutants may occur when soil physicochemical properties change. Hence, the reclamation process should be applied only to the surface layer of the soil $(30-50 \mathrm{~cm})$, and permanent monitoring is necessary (Martin and Ruby, 2004). Heavy metals immobilization in soil is generally carried out 
BAJOPAS Volume 14 Number 1, June, 2021

by using organic and inorganic amendment to soils (Ashraf et al., 2016).

- Solidification/Stabilizing: Heavy metals can be left on site and treated in a way that reduces or eliminates their ability to adversely affect human health and the environment. This process is sometimes called stabilization. Eliminating the bioavailability of heavy metals on site has many advantages over excavation. One way of stabilizing heavy metals consists of adding chemicals to the soil that cause the formation of minerals that contain the heavy metals in a form that is not easily absorbed by plants, animals, or people (Lasat, 2002). This process does not disrupt the environment or generate hazardous wastes. Instead, the heavy metal combines with the added chemical to create a less toxic compound. The heavy metal remains in the soil, but in a form that is much less harmful (Alkorta et al., 2004).

(iv). Biological Remediation: Bioremediation is a technology that uses microorganisms to treat contaminants through natural biodegradation mechanisms (intrinsic bioremediation) or through the enhancement of such capacity with the addition of microbes, nutrients, electron donors, and/ or electron acceptors (enhanced bioremediation) (EPA, 2001). The microorganisms cannot degrade or destroy the heavy metals but can affect the migration and transformation by changing their physical and chemical characterizations (Faisal et al., 2004). The process is ecologically safe and natural, and is generally $60-70 \%$ less costly than other technologies. Bioremediation is vulnerable to variables such as temperatures, oxygen, moisture, and $\mathrm{pH}$ value. Its applications can also be limited to some microorganisms that can only degrade special contaminants (Zhang et al. 2001).

- Phytoremediation: Phytoremediation basically refers to the use of plants and associated microorganisms to partially or completely remediate selected contaminants from soil, sludge, sediments, wastewater and ground water. It can be used for removal of radionuclides, organic pollutants as well as heavy metals (Ali et al., 2013). Phytoremediation utilizes a variety of plant processes and the physical characteristics of plants to aid in remediation of contaminated sites. Over the recent years, a special emphasis has been placed on phytoremediation since this property can be exploited for remediation of heavy metal polluted soils (Robinson et al., 1997).

- Phytoextraction: The initial step of phytoremediation is phytoextraction, the uptake of contaminants from soil or water by plant roots and their translocation to and accumulation in biomass, i.e., shoots (Sekara et al., 2005) Translocation of metals to shoots is an important biochemical process and is desirable in an effective phytoextraction. Some plant species can take up heavy metals and concentrate them in their tissue. The plants can be harvested and the contaminated plant material disposed of safely. Sometimes soil amendments are added to the soil to increase the ability of the plants to take up the heavy metals. Phytoextraction is done with plants called hyperaccumulators, which absorb unusually large amounts of metals in comparison to other plants. Phytoextraction is no doubt a publicly appealing green technology (Jadia and Fulekar, 2008).

- Phytostabilization: The process involved reducing the mobility and bioavailability of metals in the environment and thus prevents their migration into groundwater or the food chain (Erakhrumen, 2007). The plants are used to reduce wind and water erosion that spread materials containing heavy metals. If all of the ground could be re-vegetated, sediment loss could be cut by approximately $70 \%$. However, it would be necessary to find plants that could tolerate high levels of heavy metals (Vyslou`zilov'a, et al., 2003).

- Phytofiltration: The next important process of phytoremediation is phytofiltration, which includes rhizofiltration (use of plant roots), blastofiltration (use of seedlings) or caulofiltration (use of excised plant shoots) (Migula, et al., 2004). In this, the metals are absorbed or adsorbed and thus their movement in underground water is minimized (EPA, 2001). Heavy metals are removed directly from water by plant roots. The plants are grown directly in water or in water rich materials such as sand, using aquatic species or hydroponic methods.

\section{Limitations of Remediation Techniques}

Management of soil pollution is a major economic challenge world-wide. In addition to societal and environmental acceptability aspects, 
BAJOPAS Volume 14 Number 1, June, 2021

cost involved is the key factor determining the success and practical application of remediation technology in the field conditions.

There exist several important factors and limitation which can affect the selection and applicability of available soil clean-up technologies. These factors/limitations include:

\section{Physical Remediation}

- Large in working volume, production of dangerous waste and negative effect on soil.

- Soil clean up still needs further engineering measures; effectiveness varies with the type of subsurface barrier

- High cost due to energy requirement

- Requires soil with low permeability and $\mathrm{pH}$ needs to be controlled

\section{Chemical Remediation}

- Temporary solution and permanent monitoring is necessary.

- Washing extractants may cause environmental issue, effectiveness varies with soil, metal and extractant type (Shahid et al., 2012).

\section{Biological Remediation}

- Restricted to volatile metals

- May cause other environmental issues, no control after metal release to atmosphere.

- Temporary solution, effectiveness varies with soil, plant and metal type.

- Effectiveness depends on growing conditions, tolerance of the plant.

- Metal accumulator plants are generally very less in number.

- Costly, can be disruptive, effective for low-moderately contaminated soils, groundwater contamination risk, depends on microorganism, soil, plant and metal type.

\section{CONCLUSION AND RECOMMENDATION}

Soil is a very unique part of the natural and agricultural aspects of the terrestrial ecosystem, given its role in the growth of plants and the degradation and recycling of dead biomass. Soils

\section{REFERENCES}

Agbede, I.O. and Adegoye, M.S. (2003). Assessment of the Quality of Borehole Water in Benue State, Nigeria. Journal Agriculture Science \& Technology 13(1): 38-50.

Ali, H., Khan, E., Sajad, M.A. (2013). Phytoremediation of heavy metalsConcepts and applications. Chemosphere 91, 869-881. may become contaminated by the accumulation of heavy metals and metalloids through emissions from different resources (Aruleba and Ajayi, 2012). Heavy metals have been proved to be toxic to both human and environmental health (Kampa and Castanas, 2008). Owing to their toxicity and their possible bioaccumulation, these compounds should be subject to mandatory monitoring, background knowledge of the sources, chemistry, and potential risks of toxic heavy metals in contaminated soils is necessary for the selection of appropriate remedial options (Khan et al., 2008). Remediation of soil contaminated by heavy metals is necessary in order to reduce the associated risks, make the land resource available for agricultural production, enhance food security, and scale down land tenure problems. Different techniques are frequently listed among the best demonstrated available technologies for remediation of heavy metalcontaminated sites.Immobilization, soil washing, and phytoremediation are frequently listed among the best available technologies for cleaning up heavy metal contaminated soils but have been mostly demonstrated in developed countries (Tampouris et al., 2001). These technologies are recommended for field applicability and commercialization in the developing countries also where agriculture, urbanization, and industrialization are leaving a legacy of environmental degradation.

Governments should promote harmonized data collection, research, legislation and regulations, and consider the use of indicators, provide useful data helping to set standards and guideline values designed to protect human and environmental health from heavy metals contaminants. Exposure measurements are essential for the protection of high risk populations and subgroups. Furthermore, governments should, when setting acceptable levels or criteria related to chemicals, take into consideration the potential enhanced exposures and/or vulnerabilities of children.

Alloway, B.J. (2013). Heavy metals in soils: Trace metals and metalloids in soils and their bioavailability, Environmental pollution, Vol. 22, pp. 50-102. White knights, UK: Springer.

Alkorta, I., Hernández-Allica, J., Becerril, J.M., Amezaga, I., Albizu, I. and Garbisu, C. (2004). Recent findings on the phytoremediation of soils contaminated with environmentally toxic heavy metals 
BAJOPAS Volume 14 Number 1, June, 2021 and metalloids such as Zinc, Cadmium, Lead, and Arsenic. Rev. Environ. Sci. Biotechnol. 3,71-90

Alshawabkeh, A.N. and Bricka, R.M. (2013). Basics and application of electrokinetics remediation, Remediation engineering of contaminated soils (pp. 95-111). New York, NY: Marcel Dekker.

Armah, F.A., Quansah, R. and Luginaah, I.A. (2014). Systematic Review of Heavy Metals of Anthropogenic Origin in Environmental Media and Biota in the Context of Gold Mining in Ghana. International Scholarly Research Notices. 2014.

Aruleba, J.O. and Ajayi, A.S. (2012). Heavy metal pollution status of soils in some locations in Ado Ekiti, Southernwestern, Nigeri. International Journal Agro Sci. 2(3): 256-264.

Ashraf, A., Bibi, I., Niazi, N.K., Ok,Y.S., Murtaza, G., Shahid, M. (2016). Chromium(VI) immobilization efficiency of acid-1 activated banana peel over organo montmorillonite in aquatic environments. Int. Journal Phytoremediation. 139(3): 118-124.

ATSDR, (2007). Agency for Toxic Substances and Disease Registry. Toxicological Profile for Lead U.S. Department of Health and Humans Services, Public Health Humans Services, Centers for Disease Control. Atlanta

Baumann, T., Muller, S. and Niessner, R. (2002). Migration of dissolved Heavy Metal compounds and PCP in the presence of colloids through heterogeneous calcareous gravel and a homogeneous quartz sand-pilot scale experiments. Water Res. 36: 12131223.

Coskun, M., Stieness, E. and Franstasyeva, M.V. (2006). "Heavy Metal Pollution of Surface Soil in the Thrace Region, Turkey, Environmental Monitoring and assessment, 119 (1): 545-556.

Chen, H.M., Zheng, C.R., Tu, C. and Zhu, Y. G. (1999). "Heavy metal pollution in soils in China: status and countermeasures," Ambio, 28(2):130-134.

Chaney, R. L., Reeves, P. G., Ryan, J. A., Simmons, R. W., Welch, R. M., and Angle, J.S. (2004). An improved understanding of soil Cd risk to humans and low cost methods to phytoextract Cd from contaminated soils to prevent soil Cd risks. BioMetals, 17(5):549-553.
Chirenje, T., Ma, L.Q., Clark, C. and Reeves, M. (2003). Cu, $\mathrm{Cr}$ and As distribution in soils adjacent to pressure-treated decks, fences and poles. J. Environ. Pollut. 124: 407-417.

Duffus, J.H. (2002)."Heavy Metals" A Meaningless Term. Pure and Applied Chemistry 74,793-807.

Erakhrumen, A.A. (2007). Phytoremediation: An environmentally sound technology for pollution prevention, control and remediation in developing countries. Educ. Res. Rev. 2007, 2,151- 156.

EPA. (2001). Use of bioremediation at superfund sites. Solid waste and emergency response (5102G). U.S. Environmental Protection Agency Office of Solid Waste and Emergency Response Technology Innovation Office, Washington, DC, 20460.

ESTCP. (2000). Environmental security technology certification program. In-situ electrokinetic remediation of metal contaminated soils technology status report, US Army Environmental Center Report Number; SFIM-AEC-ETCR99022.

Faisal, I., Tahir, H., \& Ramzi, H. (2004). An overview and analysis of site remediation technologies. Journal of Environmental Management, 71(1):95-122.

Gimmler, H., Carandang, J., Boots, A., Reisberg, E. and Woitke, M. (2002). Heavy metal content and distribution within a woody plant and after seven years continuous growth on municipal solid waste (MSW) bottom slag rich in heavy metals. Appl Bot. 76: 203-217

Ghani, A. (2011). Effects of chromium toxicity on growth, chlorophyll and some mineral nutrients of Brassics juncea L. Egyptian Acad J Biol Sci 2(1): 9-15.

Ganeshamurthy, A.N., Varalakshmi, L.R. and Sumangala, H.P. (2008). Environmental Risk Associated with Heavy Metals contamination in Soils, Water and Plants in Urban and Per urban Agriculture. Journal of Horticulture, Sci. 3(1): 1-29.

Gray, C.W., Mclaren, R.G., Roberts, A.H.C., and Condron, L.M. (1999). The effect of long-time phosphatic fertilizer applications on the amounts and forms of cadmium in soils under pasture in New Zealand. Nutrient Cycling in Agroecosystem. 1999; 54: 267-277. 
BAJOPAS Volume 14 Number 1, June, 2021

Hong, A.H., Law Puong ling, S. and Onni, S. (2014). Heavy metals concentration levels in soil at Lake Geriyo irrigation Site, Yola, Adamawa State North eastern Nigeria. International Journal of Environmental Monitoring and analysis, 2(2): 106-111.

Hussein, K.O., Olalekan, S.F., Folahan, A.A., Bhekumasa, J.X. and Reinette, G.S. (2012). A Review of Sequential Extraction Procedures for Heavy Metals Specification in Soil Sediments. 1:181.

Ideriah, J.K., Pietrini, F., Flore, L., Petrilli, L., and Massacci, A. (2005). Antioxidant response to Cadmium in Phragmitesaustralis plants. Plant Physiology and Biochemistry 40(11): 977982.

International Agency for Research on Cancer (IARC). (1990). Chromium, nickel and welding. IARC Monographs Evaluation on Carcinogenic Risks Human, 49, 1648.

Jadia, C.D. and Fulekar, M.H. (2008)." Phytotoxicity and remediation of heavy metals by fibrous root grass

(sorghum)," Journal of Applied Biosciences, 10(1):491-499.

Jaishankar, M., Tseten, T., Anbalagan, N., Mathew B.B. and Beeregowda K.N. (2014). Toxicity, mechanism and health effects of some heavy metals. Interdisciplinary Toxicology. 7(2): 6072.

Kabata-Pendias, A. and Pendias, H. (1992). Trace Elements in the Soil and Plants. $2^{\text {nd }}$ edition, CRC press, Boca Raton.

Kabata-Pendias, A. and Pendias, H. (2001). Trace elements in the soil and plants. Third edition. CRC press LLC, Boca Raton, FL.

Khan, S., Cao, Q., Zheng, Y.M., Huang, Y.Z and Y. G. Zhu, Y.G. (2008)."Health risks of heavy metals in contaminated soils and food crops irrigated with wastewater in Beijing, China," Environmental Pollution, 152(3):686692.

Karami, N., Clemente, R., Moreno-Jim 'enez, E., Lepp, N., and Beesley, L. (2011). "Efficiency of green waste compost and biochar soil amendments for reducing lead and copper mobility and uptake to ryegrass," Journal of Hazardous Materials, 191(3):41-48.

Khlifi, R., Hamza-Chaff, A. (2010). Head and neck cancer due to heavy metal exposure via tobacco smoking and professional exposure: A review. Toxicol Appl Pharmacol 248: 71-88.

Kampa, M. and Castanas, E. (2008). Human Health Pollution. Environ pollut. 151(2):362-7.

Luo, Q.S., Zhang, X. H. and Wang, H. (2004). Mobilization of 2,4-dichlorophenol in soils by non- uniform electrokinetics. Acta Scientiae Circumstantiae, 24, 1104-1109.

Li, J., Zhang, G.N. and Li, Y. (2010). Review on the remediation technologies of POPs. Hebei Environmental Science, 65(8):1295-1299.

Lasat, M.M. (2002). Phytoextraction of toxic metals: A review of biological mechanisms. Journal of Environmental Quality, 31(1):109-120.

Mallampati, S.R., Mitoma, Y., Okuda, T., Simion, C. and Lee., B.K. (2015). Dynamic immobilization of simulated radio nuclide 133C sin soilby thermal treatment/vitrification with nano metallic $\mathrm{Ca} / \mathrm{CaO}$ composites. Journal. Environ. Radioact. 139, 118-124.

Martin, T.A. and Ruby, M.V. (2004). Review of in situ remediation technologies for lead, zinc and cadmium in soil. Remediation Journal, 14 (5):35-53.

Ma, Q.Y. and Dong, Y. (2004). Effects of incubation on solubility and mobility of trace metals in two contaminated soils. Environ. Pollut. 130: 301-307.

Migula, M., Mesjasz-Przybylowicz, Nakonieczny, J., Augustyniak, P., M., Tarnawska, M., Reimold, W.U., Koeberl, C., Przybylowicz, W. and Glowacka, E. (2004). Uptake of cadmium, lead, nickel and zinc from soil and water solutions by the nickel hyperaccumulator Berkheya coddii. Acta Biol.Cracov. Bot. 2004, 46, 75-85.

Mo, L.S., Moo, C.C. and Ho, Y.S. (1999), Specification of $\mathrm{Cd}, \mathrm{Cu}$, and $\mathrm{Zn}$, in sewage sludge treated soils incubated under aerobic and unaerobic conditions. Agric. Chem. Biotechnol. 42: 85-91.

Malandrino, M., Abollino, O., Buaso S., Giacomino, A., Giola, C. and Mentasti E. (2011). Accumulation of heavy metals from contaminated soil to plants and evaluation of soil remediation by vermiculite.

Chemosphere 82(2011): 169-178.

Merian, E., Anke, M., Inhat, M. and Stoeppler, M. (2004). Elements and their compounds in the environment. Wiley VCH, Weinhem, Germany; 2004. 
BAJOPAS Volume 14 Number 1, June, 2021

Mohanty M. and Kumar Patra, H. (2013). Effect of ionic and chelate assisted hexavalent chromium on mung bean seedlings (Vigna Radiata I. Wikzek. Var k-851) during seedling growth. JSPB 9(2): 232-241.

Mohamed, B. and Ahamadou, M. (2010)."Fractionation of copper and cadmium and their binding with soil organic matter in a contaminated soil amended with organic materials," Journal of Soils and Sediments, 10(6):973-982.

Nestle, F.O., Speidel, H. and Speidel, M.O. (2002). Metallurgy: High nickel release from 1- and euro at coins. Nature (2002), 419:132.

Nishimura, Y., Yamaguchi, J.Y., Kanada, A,. Horimoto, K., Kanemaru, K. and Satoh, M. (2006). Increase in intracellular $\mathrm{Cd}(+2)$ Concentration of Rat Cerebellar Granule Neurons incubated With

Cadmium Chloride, Cadmium Cytotoxicity Under External $\mathrm{Ca}(+2)$ free condition. Toxicol in Vitro, 20(2):211-6.

Ogboru R.O (2001). Determination of some Heavy Metals in Soil of Some Parts of Rivers State, Nigeria. SPJTS.1(2):081-089.

Okada, I.A., Sakuma, A.M., Maid, F.D., Dovidemskas, S. and Zenebon, $O$. (1997). Evaluation of Lead and Cadmium in Milk due to Environmental Contamination in Paraiba valley region of South Eastern Brazil. RaissadeSaude-publica. 31: 140-143.

Okonkwo, N.C., Igwe, J.C. and Onwuchekwa, E.C. (2005). Risk Health Implications of Polluted Soils for Crop Production, African Journal of Biotechnology. 4(1): 2005

Ou-Yang, X., Chen, J. W. and Zhang, X. G. (2010). Advance in supercritical CO2 fluid extraction of contaminants from soil. Geological Bulletin of China, 29(11):1655-1661

Petrovic, M., Kastelan, M. and Horvet, J.M. (1999). Interactive sorption of metals ions and Humic acids into mineral Particles. Water, Air, Soil pollut. 111:4156.

Qian, S.Q. and Liu, Z. (2000). An overview of development in the soil-remediation technologies. Chemical Industrial and Engineering Process, 20(4):10-20.

Rodriguez, M.C., Barsanti, L., Passareli, V., Evangelista, V., Conforti, V. and Gualtieri, P. (2007). Effects of
Chromium on photosynthetic and photoreceptive apparatus of the alga Chlamydomonas reinharadtii. Environ Res 105(2):234-239.

Reeves, R.D. and Baker A.J.M. (2000): Metal accumulation plants. In: Phytoremediation of toxic metals: Using plant to clean up the environment. (Ed: I. Raskin and B.D. Ensely). John Wiley andSons, Inc. Torento, Canada. pp - 193-229.

Robinson, B.H., Brooks, R.R., Howes, A.W., Kirkman, J.H., Gregg, P.E.H. (1997). The potential of the high biomass nickel hyperaccumulator Berkheya coddii for phytoremediation and phytomining. Journal Geochem. Explor. 60(1):115126.

Singh, N., Kumar D. and Sahu A. (2007). Arsenic in the environment: eff ects on human health and possible prevention. Journal of Environmental Biol. 28(2):359-365.

Sauve, S., Henderson, W. and Allen, H.E. (2000). Solid -solution portion of metals in contaminated soils, dependent on $\mathrm{PH}$, total metal burden and organic matter. Env. Sci. Tech. 34:11125-1131.

Smith, L.A., Means, J.L. and Chen A. (1995). Remedial Options for MetalsContaminated Sites, Lewis Publishers, Boca Raton, Fla, USA, 1995.

Sobha, K., Poornima, A., Harini, P. and Veeraiah, K. (2007). A study on biochemical changes in the fresh water fish, catla catla (hamilton) exposed to the heavy metal toxicant cadmium chloride. Kathmandu Univ. Journal of Science Eng. and Technology 1(4): 1-11.

Sarikaya, M., Tamerler, C., Jen, A.K., Schulten, K., Baneyx, F. (2003). Molecular biomimetics: Nanotechnology through biology. Nat. Mater. 2003, 2, 577-585.

Sekara, A., Poniedzialeek, M., Ciura, J. and Jedrszczyk, E. (2005). Cadmium and lead accumulation and distribution in the organs of nine crops: implications for phytoremediation. Pol. Journal. Environ. Stud. 14(1):509-516.

Scragg, A. (2006). Environmental Biotechnology, Oxford University Press, Oxford, UK, $2^{\text {nd }}$ edition, 2006.

Stephan, A. (2000). Crystallographic Structure and Magnetic Properties of electrodeposited Cobalt and Cobalt alloys. Electrochemical acta, 2000, 45: 3323-3335

Tampouris, S., Papassiopi, N. and Paspaliaris, I. (2001). Removal of contaminant metals 
BAJOPAS Volume 14 Number 1, June, 2021

from fine grained soils, using agglomeration, chloride solutions and pile leaching techniques. Journal of Hazardous Material, 84(3):297-319.

Taylor, S.R. and McLennan, S.M. (1995). The geochemical evaluation of the continental crust, Reviews of Geophysics, 33(2):241-265.

Vanbroekhoven, K., Van Roy, S., Gielen, C., Maesen, M., Diels, L. and Seuntjens, P. (2006). Varying redox conditions changes metal behavior due to microbial activities. Geoph. Res. Abs. 8(1):02292.

Vanloon, G.W. and Duffy, S.J. (2005). Enviromental Chemistry a Global Perspective: Oxford University Press.

Vyslou`zilov'a, M., Tlusto `s, P., Sz'akov'a, J., and Pavl'ıkov'a, D. (2003)."As, Cd, Pb and $\mathrm{Zn}$ uptake by Salix spp. clones grown in soils enriched by high loads of these elements," Plant, Soil and Environment, 49(5):191-196.

Vanschol, L., Hoffland, E., and VanBreem, N. (2006) "Organic anion exudation by ectomycorrhizal fungi and Pinus sylvestris in response to nutrients deficiencies" New Phytologist,170:153163

Wang, F., Wang, Z., Kou, C., Ma, Z. and Zhao, D. (2016). Responses of wheat yield, macro- and micronutrients and heavy metals in soil and wheat following the application of manure compost on the North China plain.

Waalkes, M.P. (2000) Cadmium carcinogenesis in review. Jounal inorg. Biochem. 79(1): 241-244.

Wuana, R.A. and Okieimen, F.E. (2011). Heavy Metals in Contaminated Soils: A Review of Sources, Chemistry, Risks and Best Available Strategies for Remediation, International Scholarly Research Network, ISRN Ecology, 2011, $1-20$.

Yanagi, T. (2011). Chemical composition of continental crust and the primitive mantle, Chapter 2 in Generation of continental crust from the mantle, Arc Volcano of Japan, Lecture Notes in Earth Sciences 136, Springer-Verlag Berlin, Heidelberg, 9-17.

Yao, Z., Li, J., Xie., H. and Yu, C., (2012). Review on remediation technologies of soil contaminated by heavy metals. Procedia Environ. Sci. 16,722-729.

Yu Rui-lian, Yuan- xing, Zhao, Yuan-hui, Hu, Gong-ren, and Tu. Xian-lian. (2008). Heavy metal pollution in intertidal sediments from Quanzhou Bay, China (j). Journal of environmental Sciences, 20(6): 6664-669.

Zhang, X. H., Wang, H. and Luo, Q. S. (2001). Electrokinetics in remediation of contaminated groundwater and soils. Advances in Water Resources, 12(2):249-255

Zhang, T., Zou, H., Ji, M., Li, X., Li, L., and Tang, T. (2014). Enhanced electrokinetic remediation of lead-contaminated soil by complexing agents and approaching anodes. Environmental Science and Pollution Research, 21(4):3126-3133.

Zhang, M.K., Liu, Z.Y. and Wang, H. (2010). "Use of single extraction methods to predict bioavailability of heavy metals in polluted soils to rice," Communications in Soil Science and Plant Analysis, 41(7): 820-831.

Zhao, H., Xia, B., Fan, C., Peng, Z. and Shen, S. (2012). Human health risk from soil heavy metal contamination under different land uses near Dabaoshan Mine, Southern China, Journal Science of the Total Environment, 417-418: 45 -54 .

Zheng, C., and Wang, P.P. (2002). A field demonstration of the simulation optimization approach for remediation system design. GroundWater 40, 258265.

Zhu, L., Ding,W., Feng, L., Kong, J., Xu, Y., Xu, J., and Yang, X., (2012). Isolation of aerobic denitri- fiersand characterization for their potential application in the bioremediation of oli-gotrophic ecosystem. Bioresour.Technol.108,1-7.

Zhou, H., Zhou, X., Zeng, M., Liao, B. H., Liu, L., Yang, W. T. (2014). Effects of combined amendments on heavy metal accumulation in rice (Oryza sativa L.) planted on contaminated paddy soil. Ecotoxicology and Environmental Safety, 101, 226-232.

Zhou, D.M., Hao, X.Z., and Xue, Y. (2004). Advances in remediation technologies of contaminated soils. Ecology and Environmental Science, 13(2):234-242. 